\title{
Morphometric Analysis of Hemicerebellar Asymmetry with Central Vertigo Cases: A Stereological Study
}

\author{
Análisis Morfométrico de la Asimetría Hemicerebelar \\ en Casos de Vértigo Central: Un Estudio Estereológico
}

\author{
"Nuket Gocmen-Mas, H.; "*Selim Karabekir; ****Ozge Yilmaz Kusbeci; *****Bunyamin Sahin; \\ ${ }^{* * * * * *}$ Tolga Ertekin; ${ }^{* * * * * * *}$ Orhan Bas; ${ }^{* * * * * * *}$ A. Canan Yazici \& "Sevda Senan
}

GOCMEN-MAS, H. N.; KARABEKIR, S.; YILMAZ K. O.; SAHIN, B.; ERTEKIN, T.; BAS, O.; CANAN Y. A. \& SENAN, S. Morphometric analysis of hemicerebellar asymmetry with central vertigo cases: a stereological study. Int. J. Morphol., 28(2):637-642, 2010.

SUMMARY: We aimed to evaluate the relevant methods of stereology to estimate hemicerebellar asymmetry according to sex in both adult right handed vertigo cases and comparing with healthy cases. The study included 14 adult control subjects and 18 patients with vertigo. The volumes of the cerebellar hemispheres were determined by MRI using the point-counting approach of stereological methods. The mean $( \pm \mathrm{SD})$ of the right cerebellar hemispheres in the patients with vertigo were $52.49 \pm 5.42 \mathrm{~cm} 3 \mathrm{in}$ males, $50.11 \pm 4.02$ $\mathrm{cm} 3$ in females. The mean $( \pm \mathrm{SD})$ of the left cerebellar hemispheres in the patients with vertigo were $53.11 \pm 3.70 \mathrm{~cm} 3 \mathrm{in} \mathrm{males,} 49.73 \pm 4.69$ $\mathrm{cm} 3$ in females. There was not significant quantitative evidence detected in terms of cerebella asymmetry between sagittal plane estimates in the cases with vertigo in both genders $(\mathrm{p}>0.05)$. There were no statistically significant differences according to the genders between both vertigo and control subjects $(\mathrm{p}>0.05)$. There was only statistical significance between right and left hemispheres in male control subjects $(\mathrm{p}=0.039)$. There was no cerebella asymmetry between control and vertigo cases according to genders. The stereological evaluation of cerebella asymmetry or atrophy in humans correlate with gender is of importance for both clinicians and anatomists. The technique is simple, reliable, inexpensive and unbiased.

KEY WORDS: Cavalier principle; Stereology; Hemicerebellar asymmetry; Magnetic resonance imaging; Vertigo.

\section{INTRODUCTION}

Vertigo is an illusion of movement, usually rotation, although patients occasionally describe a sensation of linear displacement or tilt and it occurs when an imbalance or disturbance in vestibular function occurs anywhere in the peripheral and central vestibular system and it is associated with several different disorders. Asymmetry of neural activity between left and right vestibular nuclei is the most important reason of true rotator vertigo, where as more nonpsecific vertigo symptoms are caused by cerebellar dysfunction, vasodepressor syncope, postural hypotension, cardiac dysrhythmia, peripheral neuropathy, anxiety, and hypoglycemia. Vertigo is always temporary and abates within a few days as central compensation occurs (Bruzzone et al., 2004; Weinberger et al., 1980). Signs and symptoms of dysfunction of neighboring structures include the central brainstem and cerebellar structures in central causes of vertigo (Brazis et al., 1990).

Several studies focused on the determination of brain compartments and tried to find MRI detectable discriminators of healthy and pathological aging in neurodegenerative diseases (Bernasconi et al., 2003; Ho et al., 2003; Edland et al., 2002). Asymmetric and volumetric changes in cerebellar anatomy has been an interesting subject

Afyon Kocatepe University, Anatomy, Afyonkarahisar, Turkey

** Afyon Kocatepe University, Neurosurgery, Afyonkarahisar, Turkey

**** Afyon Kocatepe University, Neurology, Afyonkarahisar, Turkey

***** Ondokuz Mayıs University, Anatomy, Samsun, Turkey

****** Kocatepe University Ataturk Vocational School of Health Services, Anatomy, Afyonkarahisar, Turkey

******* Rize University School of Medicine, Anatomy, Rize, Turkey

******** Baskent University, School of Medicine, Biostatistics, Ankara, Turkey 
for researchers (Gocmen-Mas et al., 2009; Robins et al., 1998). MRI-based volume quantification is now being increasingly used to investigate neuroanatomical structures in neurological and psychiatric disorders, e.g. schizophrenia, Alzheimer's disease, and epilepsy (Bernasconi et al.; Ho et al.; Murphy et al., 2003). MRI is useful in the quantitative evaluation of asymmetrical changes of cerebella because the superior contrast resolution facilitates separation of the gray and white matter. Quantitative assessment of hemicerebellar asymmetry has mainly been performed by manual measurement, which requires considerable time and effort to determine the hemicerebella volume.

Some authors investigated volumetric analysis of different cerebellar regions as the anterior and posterior lobe, the vermis and the flocculonodular lobe. They found total cerebellar volume loss was obtained during aging process but they concluded only male subjects and did not evaluate cerebellar asymmetry (Andersen et al., 2003; Andersen \& Pakkenberg, 2003). According to many authors the cerebellum does not have a symmetrical morphology. As an example, dextrals show more asymmetry than non dextrals (Sato et al., 2007). On the other hand some pathological disorders such as schizophrenia, epilepsy, cerebellar hypoplasia, hemimegalencephaly, dyslexia, autism, alcoholism, drug abuse, bipolar disorder, brain injuries or tumors could also cause asymmetrical changes in the cerebellar morphology (Ammerman et al., 2007; Benegal et al., 2007; Sato et al.; Sim et al., 2007; Guerrini et al., 2004; Robins et al.). Thus, a detailed knowledge on the asymmetrical structure of cerebellum and changes in this morphology related with gender in sagittal plane would be of importance for a reliable diagnoses and neurosurgical approach.

It is important to evaluate cerebellar asymmetry based on gender in both axial and sagittal cross sectional images of MRI combined by stereological technique is of crucial importance for both the anatomists and the neurologists (Andersen et al.; Andersen \& Pakkenberg; Bruzzone et al.; Traccis et al., 2004). In this way it is aimed that different pathologies in brain tissue defined by clinicians can be compared to the stable database in the present study.

Hence, we aimed to evaluate the hemicerebellar asymmetry of the patients with vertigo disease using a stereological technique depending on sex in sagittal plane. The requirement for the application of the stereological method is an entire set of two-dimensional slices through the object, provided they are parallel, separated by a known distance, and begin randomly within the object, criteria that are met by standard MR imaging technique (Roberts et al., 2000; Sahin \& Ergur, 2006). In the literature, there is no data about evaluation of hemicerebellar asymmetry in vertigo disease using stereological technique.

\section{MATERIAL AND METHOD}

Magnetic resonance image data. MR images of the subjects including 14 (7 men, 7 women) healthy control and 18 (8 men, 10 women) right handed adult patients with vertigo, aged between 26-50 years were examined, retrospectively. All subjects were admitted to the Department of Neurology and Neurosurgery in Afyon Kocatepe University Faculty of Medicine, with severe disturbances such as dizziness. All the patients underwent auto neurological examination, auditory evoke potentials registration and MRI. The patients with cerebrovascular disease, Multiple Sclerosis, Epilepsy, cerebellar or cerebellopontine angle tumors, spondylosis, depressive state, poor vision, orthostatic hypotension, whiplash injury, vestibular disorders such as neuritis, peripheral cochleovestibular syndromes etc. or low cerebrospinal fluid syndrome were excluded. Inform contents of the patients both study and control groups were obtained.

Standard T1-weighted axial and sagittal plan (5 mm) slices were obtained at the suggestion of radiology specialist, and were used in order to compute the cerebellar hemisphere volumes in a 1.5-T MR machine (Philips Systems, Netherlands). A spoiled pulse gradient recalled (SPGR) acquisition in the steady state was used. This is a three dimensional volume gradient echo pulse sequence that is radiofrequency spoiled. A sagittal localizer was first acquired, and the volume of interest was then arranged to include the whole brain. The three-dimensional SPGR sequence was acquired over a period of $14 \mathrm{~min}$. The MRI parameters were as follows; time of repetition (TR) of $35 \mathrm{~ms}$ and a time echo (TE) of $15 \mathrm{~ms}$; the echo was $1 / 1$ with $16 \mathrm{kHz}$. The flip angle was $35^{\circ}$. Because image data were collected retrospectively, the data set contained image matrix: Matrix of $256 \bullet 256$ pixels $\bullet 124$ slices for a FOV of $24 \bullet 24$ x $18.6 \mathrm{~cm}$, respectively. Thus, image voxels are $0.09375 \bullet 0.09375 \bullet 1.5 \mathrm{~cm}$.

Stereological analysis. Both whole and hemicerebellar volumes computed from each image were measured three times by three observers using a stereological method. All measurements were performed blinded to subject details and the results of any other measurements. An optimal plan was taken as the smallest diameter of anisotropic structures that can be measured in volumetric analysis of sagittal and axial cranial MRI sections. Original MR Images were exported as if image files and further stereological analysis were done using these image sets with the aid of Image-J software. A 
uniform point-grid with a point-associated area of $0.625 \mathrm{~cm}^{2}$ was randomly superimposed on each MR image using the "Grid" plug-in installed with Image-J. Points hitting the cerebella were manually counted for volume estimation. Volume estimation was accomplished by the Cavalier's principle as described previously (Acer et al., 2008; Ekinci et al., 2008; Kalkan et al., 2007; Sahin \& Ergur) using the formula given below:

$$
V=t \times[((S U) \times d) / S L] 2 \times S P
$$

where, $\mathrm{t}$ is the section thickness, $\mathrm{SU}$ is the scale unit (the real length of the scale marked on the MRIs), $d$ is the distance between two points in the point grid, SL is the scale length (the actual measure of the scale on MRIs) and $\mathrm{P}$ is the number of points counted. All data have been entered in a previouslyprepared Microsoft excel spreadsheet for automatic calculation of both the results of the above formula and the statistical evaluation parameters including the nugget variance and the coefficient of error $(\mathrm{CE})$.

In order to evaluate the hemispheric asymmetry between cerebellar hemispheres, middle sections were identified by the clear visualization of the cerebral aqueduct. The point counts belonging to the middle section is divided by two and the results were added to the total point counts for each hemisphere separately, and thus, a volume value for each cerebellar hemisphere has been estimated. The stereological point counting method has been demonstrated in Fig. 1. Statistical analyses were made afterwards and the results were standardized to generate a normal database.

Statistical analysis. Distributions of the variables were analyzed by Shapiro-Wilk normality test. Homogeneity of the groups' variances was controlled by Levene's test. Parametric test assumptions were satisfied, and differences between left and right cerebellum volume means of control and vertigo groups according to sex were analyzed by Three Factorial Repeated Measures Analysis of Variance. Results have been expressed as numbers of observations (n) and mean \pm standard deviation (SD). $p$ value less than 0.05 was considered as statistically significant. All statistical analyses were performed with the SPSS software (Statistical Package for the Social Sciences, version 13.0, SSPS Inc, Chicago, IL, USA).

\section{RESULTS}

Mean values for hemispheres of cerebella volume calculated according to stereological point counting method are listed in Table I. The mean $( \pm \mathrm{SD})$ of right cerebellar hemispheres $(\mathrm{RCH})$ in control group were $46.50 \pm 4.84 \mathrm{~cm} 3$ in males, $48.47 \pm 9.56 \mathrm{~cm}^{3}$ in females in sagittal plane. The mean $( \pm \mathrm{SD})$ of the left cerebellar hemispheres $(\mathrm{LCH})$ in control group were $51.56 \pm 4.17 \mathrm{~cm}^{3}$ in males, $52.33 \pm 5.52$ in females in sagittal plane. The mean $( \pm \mathrm{SD})$ of the $\mathrm{RCH}$ in the patients with vertigo were $52.49 \pm 5.42 \mathrm{~cm}^{3}$ in males, $50.11 \pm 4.02 \mathrm{~cm}^{3}$ in females in sagittal plane. The mean $( \pm \mathrm{SD})$ of the $\mathrm{LCH}$ in the patients with vertigo were 53.11 \pm 3.70 $\mathrm{cm}^{3}$ in males, $49.73 \pm 4.69 \mathrm{~cm}^{3}$ in females in sagittal plane. There was no significant quantitative evidence detected in terms of cerebellar asymmetry between sagittal plane estimates in the cases with vertigo $(\mathrm{p}>0.05)$. There were also no statistically significant differences according to the genders between both vertigo and control subjects ( $\mathrm{p}>0.05)$. There was only statistical significance between right and left hemispheres in male control subjects $(\mathrm{p}=0.039)$.

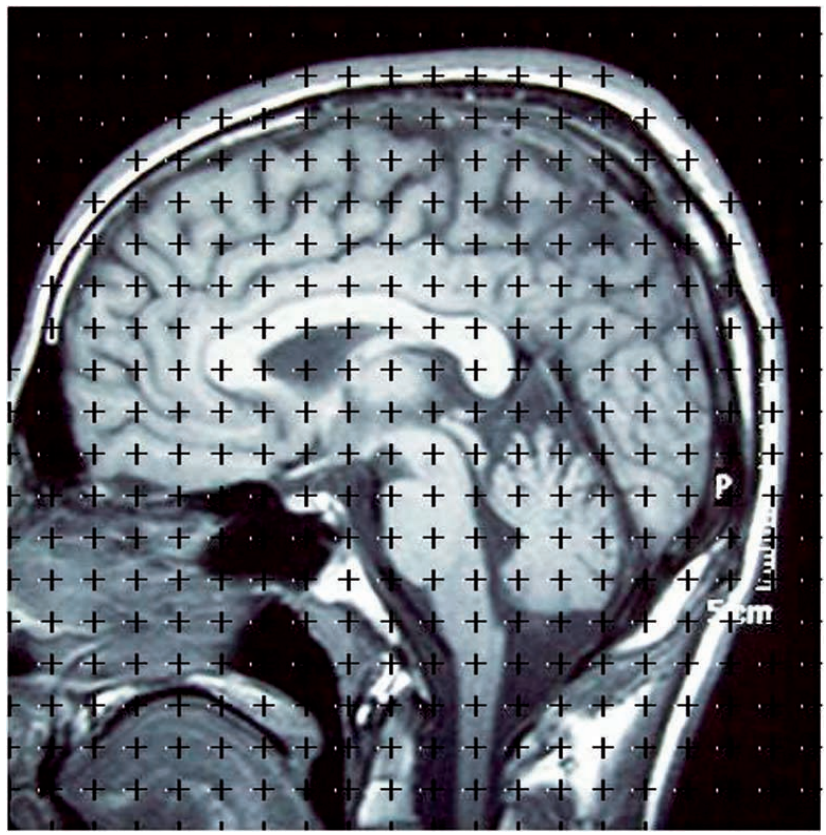

Fig. 1. The method of counting points has been demonstrated on a sagittal brain MR imaging section

Table I. Mean values of control and study groups' cerebellum hemispheres according to gender. *p<0.05.

\begin{tabular}{ccccccccc}
\hline Cerebellum & \multicolumn{2}{c}{ Control } & Mean \pm SD & \multicolumn{3}{c}{ Vertigo } & Mean \pm SD \\
\hline & \multicolumn{2}{c}{ Left side } & \multicolumn{2}{c}{ Right side } & \multicolumn{2}{c}{ Left side } & \multicolumn{2}{c}{ Right side } \\
Male & $\mathrm{n}=7$ & $51.56 \pm 4.17 *$ & $\mathrm{n}=7$ & $46.50 \pm 4.84$ & $\mathrm{n}=8$ & $53.11 \pm 3.70$ & $\mathrm{n}=8$ & $52.49 \pm 5.42$ \\
Female & $\mathrm{n}=7$ & $52.33 \pm 5.52$ & $\mathrm{n}=7$ & $48.47 \pm 9.56$ & $\mathrm{n}=10$ & $49.73 \pm 4.69$ & $\mathrm{n}=10$ & $50.11 \pm 4.02$ \\
\hline
\end{tabular}




\section{DISCUSSION}

Neuroanatomical, neuroimaging and behavioral reports of cerebella in cognitive and language functions increasingly enclose the cerebellum as the site of morphological changes occurring in neuropsychiatric diseases (Bruzzone et al.; Traccis et al.; Weinberger et al.).

MRI analysis allows determining quantitative analysis of cerebella and morphological evaluation of brain in vivo (Acer et al.) Many authors evaluated volume changes of cerebellum according to age and gender in healthy subjects. They claimed that female subjects had significantly smaller cerebellar volumes compared with males of similar age (Carne et al., 2006; Tang et al., 2001). Gocmen-Mas et al., found that the reduction of the cerebellar volume was not statistically significant and there was no cerebellar asymmetry according to age and gender in healthy subjects. The relationship of the gender of the subject and cerebellar size is not clear and there are conflicting reports in the literature (Acer et al.; Sim et al.; Escalona et al., 1991). Although the literature includes many studies about volume changes of cerebellum according to age and gender, there is no data about hemicerebellar asymmetry related to gender in adult cases of vertigo. Some pathological conditions such as cerebellar hypertrophy, atrophy, agenesis and architectural alterations could also cause asymmetrical changes between right and left hemispheres (Gocmen-Mas et al.; Sato et al.) Asymmetric alterations of cerebella can lead to much different pathologies. Hemicerebellar asymmetric enlargement was reported in intractable epilepsy (Sato $e t$ $a l$.). Unilateral atrophy of a cerebellar hemisphere occurring as a sequel of ischemic or destructive injury was reported. They investigated age-related atrophy of cerebellum by MRI using stereological methods in older people (Rollins et al., 1995; Tang et al.). Thus, we aimed to evaluate whether cerebellar hemispheric asymmetry is present or not in the cases of vertigo. Thus, mean values for hemispheres of cerebella volume was calculated according to stereological point counting method.

In morphometrical studies, the volume of an organ or its components, the volume of the variable component in a structure are frequently investigated via different measurement techniques (Kalkan et al.; Luft et al., 1998; 1997; Andreasen et al., 1996; Andersen et al.; Andersen \& Pakkenberg). In the present study, we used the stereological method for the estimation of cerebellar asymmetry according to gender in the adult cases with vertigo since the previous study showed that the method (Gocmen-Mas et al.; Acer et $a l$.). Cavalier principle of stereological approaches by point counting consists of overlying each selected section with a regular grid of test points, which is randomly positioned. The Cavalier theorem of systematic sampling in combination with point counting is considered a reliable, simple, inexpensive and efficient method for estimating volumes in MRI (Gocmen-Mas et al.; Acer et al.; Cruz-Orive et al., 1983). However, the safest method is undoubtedly to reduce section thickness as much as technically possible while maintaining an acceptable image quality.

Ekinci et al. used MRI obtained from 24 normal volunteers ranging from 20-25 years of age and measured total brain, cerebrum and cerebellum volume. They found that the mean cerebellum volumes were 117.75 in males and $111.83 \mathrm{~cm} 3$ females (Ekinci et al.). They also claimed that cerebellar volumes were slightly larger in females but smaller in males than those reported by Escalona et al., $104 \mathrm{~cm}^{3}$ in female and $122 \mathrm{~cm}^{3}$ in male and Rhyu et al., $115.4 \mathrm{~cm}^{3}$ in female and $126 \mathrm{~cm}^{3}$ in male smaller than those of Luft et al. mean $134.3 \mathrm{~cm}^{3}$ in both sexes and similar to Dupuis (Ekinci et al.; Rhyu et al., 1999; Luft et al., 1998; 1997; Rollins et al.; Escalona et al.). It's not clear that discrepancy may be due to the racial difference or is the due to the variation resulting from different scanning protocols and measuring methods used. Ekinci results revealed that the volumetric composition of the cerebellum does not show sexual dimorphism. We found that right hemisphere of cerebellum was smaller than the left in control male subjects. There were no asymmetric differences in vertigo for either sexes. The present evaluation of cerebella hemisphere volumes can be done on any complete set of MRI, where plane scan distance and magnification factor is known, which already take place on the MRI. The stereological evaluation of hemicerebellar asymmetry or atrophy in humans correlate with sex is of importance for both clinicians and anatomists. The technique is simple, reliable, unbiased and inexpensive. The data of the present study can large enough to be meaningful for anatomists and clinicians. Further studies are required with larger samples in order to support these data.

GOCMEN-MAS, H. N.; KARABEKIR, S.; YILMAZ K. O.; SAHIN, B.; ERTEKIN, T.; BAS, O.; CANAN Y. A. \& SENAN, S. Análisis morfométrico de la asimetría hemicerebelar con casos de vértigo central: un estudio estereológico. Int. J. Morphol., 28(2):637-642, 2010.

RESUMEN: Nuestro objetivo fue evaluar los métodos relevantes de estereología para estimar la asimetría hemicerebellar según el género, tanto en adultos diestros, casos de vértigo y al compararlos con casos control. El estudio incluyó a 14 sujetos adultos como control y 18 pacientes con vértigo. Los volúmenes de los hemisferios del cerebelo se determinaron en la RM utilizando el recuento de los puntos del método de estereología. La media $( \pm$ DE) de los hemisferios derecho del cerebelo en los pacientes con 
vértigo fueron $52,49 \pm 5,42 \mathrm{~cm} 3$ en los hombres, $50,11 \pm 4,02 \mathrm{~cm} 3$ en las mujeres. La media ( $\pm \mathrm{DE})$ de los hemisferios izquierdo del cerebelo en los pacientes con vértigo fueron $53,11 \pm 3,70 \mathrm{~cm} 3$ en los hombres, 49,73 $\pm 4,69 \mathrm{~cm} 3$ en las mujeres. No hubo evidencia cuantitativa importante detectada en cuanto a la asimetría entre las estimaciones del cerebelo entre plano sagital en los casos con vértigo en ambos sexos $(p>0,05)$. No hubo diferencias estadísticamente significativas según los géneros entre ambos el vértigo y los sujetos control ( $\mathrm{p}>0,05)$. Sólo hubo significancia estadística entre los hemisferios derecho e izquierdo en los sujetos control masculino $(p=0,039)$. No hubo asimetría entre el cerebelo control y de los casos el vértigo de acuerdo a los géneros. La evaluación de la asimetría estereológica o atrofia del cerebelo en el ser humano se correlaciona con el género es de importancia para los clínicos y anatómicos. La técnica es simple, confiable, de bajo costo e imparcial.

PAlabras Clave: Principios de Cavalieri; Estereología; Asimetría hemicerebelar; Imagen por resonancia magnética; Vértigo.

\section{REFERENCES}

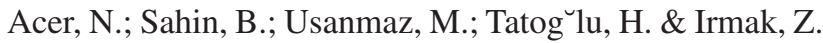
Comparison of point counting and planimetry methods for the assessment of cerebellar volume in human using magnetic resonance imaging: A stereological study. Surg. Radiol. Anat., 30:335-9, 2008.

Ammerman, J. M.; Lonser, R. R. \& Oldfield, E. H. Posterior subtemporal transtentorial approach to intraparenchymal lesions of the anteromedial region of the superior cerebellum. J. Neurosurg., 41:436-44, 2007.

Andersen, B. B.; Gundersen, H. J. \& Pakkenberg, B. Aging of the human cerebellum: a stereological study. J. Comp. Neurol., 17:466:356-65, 2003.

Andersen, B. B. \& Pakkenberg, B. Stereological quantitation in cerebella from people with schizophrenia. $\mathrm{Br} . \mathrm{J}$. Psychiatry, 182:354-61, 2003.

Andreasen, N. C.; Rajarethinam, R.; Cizadlo, T.; Arndt, S.; Swayze, V. W.; Flashman, L. A.; O'Leary D. S.; Ehrhardt, J. C. \& Yuh, W. T. Automatic atlas-based volume estimation of human brain regions from MR images. $J$. Comput. Assist. Tomogr., 20:98-106, 1996.

Benegal, V.; Antony, G.; Venkatasubramanian, G. \& Jayakumar, P. N. Gray matter volume abnormalities and externalizing symptoms in subjects at high risk for alcohol dependence. Addict. Biol., 12:122-32, 2007.
Bernasconi, N.; Andermann, F.; Arnold, D. L. \& Bernasconi, A. A. Entorhinal cortex MRI assessment in temporal, extratemporal, and idiopathic generalized epilepsy. Epilepsia, 44:1070-4, 2003.

Brazis, P. W.; Masdeu, J. C. \& Biller, J. Localization in clinical neurology. In: Biller, J. \& Brazis, P. (Eds.). The localization of lesions affecting cranial nerve VIII. $2^{\text {nd }}$ Ed. Boston, Brown \& Company, 1990. pp.229-33.

Bruzzone, M. G.; Grisoli, M.; De Simone, T. \& RegnaGladin, C. Neuroradiological features of vertigo. Neurol. Sci., 1:S20-3, 2004.

Carne, R. P.; Vogrin, S.; Litewka, L. \& Cook, M. J. Cerebral cortex: an MRI-based study of volume and variance with age and sex. J. Clin. Neurosci., 13:60-72, 2006.

Cruz-Orive, L. M. Distribution-free estimation of sphere size distributions from slabs showing overprojection and truncation, with a review of previous methods. $J$. Microsc., 131:265-90, 1983.

Edland, S. D.; Xu, Y.; Plevak, M.; O’Brien, P.; Tangalos, E. G.; Petersen, R. C. \& Jack, C. R. Jr. Total intracranial volume: normative values and lack of association with Alzheimer's disease. Neurology, 59:272-4, 2002.

Ekinci, N.; Acer, N.; Akkaya, A.; Sankur, S.; Kabadayi, T. \& Sahin, B. Volumetric evaluation of the relations among the cerebrum, cerebellum and brain stem in young subjects: a combination of stereology and magnetic resonance imaging. Surg. Radiol. Anat., 30:489-4, 2008.

Escalona, P. R.; McDonald, W. M.; Doraiswamy, P. M.; Boyko, O. B.; Husain, M. M.; Figiel, G. S.; Laskowitz, D.; Ellinwood, E. H. Jr. \& Krishnan, K. R. Invivo stereological assessment of human cerebellar volume: effects of gender and age. AJNR Am. J. Neuroradiol., 12:927-9, 1991.

Gocmen-Mas, N.; Pelin, C.; Canan, S.; Yazici, A.C.; Zagyapan, R.; Senan, S.; Karabekir, H.S. \& Sahin, B. Stereological evaluation of volumetric asymmetry in healthy human cerebellum. Surg. Radiol. Anat., 31:177$81,2009$.

Guerrini, L.; Lolli, F.; Ginestroni, A.; Belli, G.; Della Nave, R.; Tessa, C.; Foresti, S.; Cosottini, M.; Piacentini, S.; Salvi, F.; Plasmati, R.; De Grandis, D.; Siciliano, G.; Filla, A. \& Mascalchi, M. Brainstem neurodegeneration correlates with clinical dysfunction in SCA1 but not in 
SCA2. A quantitative volumetric, diffusion and proton spectroscopy MR study. Brain, 127:1785-95, 2004.

Ho, B. C.; Andreasen, N. C.; Nopoulos, P.; Arndt, S.; Magnotta, V. \& Flaum, M. Progressive structural brain abnormalities and their relationship to clinical outcome: a longitudinal magnetic resonance imaging study early in schizophrenia. Arch. Gen. Psychiatry., 60:585-94, 2003.

Kalkan, E.; Cander, B.; Gul, M.; Karabagli, H.; Girisgin, S. \& Sahin, B. A new stereological method for the assessment (prediction) of prognosis in patients with epidural hematoma: the hematoma to total brain volume fraction. Tohoku J. Exp. Med., 211:235-42, 2007.

Luft, A. R.; Skalej, M.; Welte, D.; Kolb, R.; Bürk, K..; Schulz, J. B.; Klockgether, T. \& Voigt, K. A new semiautomated three-dimensional technique allowing precise quantification of total and regional cerebellar volume using MRI. Magn. Reson. Med., 40:143-51, 1998.

Luft, A. R.; Skalej, M.; Welte, D.; Voigt, K. \& Klockgether, T. Age and sex do not affect cerebellar volume in humans. AJNR Am. J. Neuroradiol., 18:593-96, 1997.

Murphy, T. L.; Jernigan, T. L. \& Fennema-Notestine, C. Left hippocampal volume loss in Alzheimer's disease is reflected in performance on odor identification: a structural MRI study. J. Int. Neuropsychol. Soc., 9:45971, 2003.

Roberts, N.; Puddephat, M. J. \& McNulty, V. The benefit of stereology for quantitative radiology. Br. J. Radiol., 73 : 679-97, 2000.

Robins, J. B.; Mason, G. C.; Watters, J. \& Martinez, D. Case Report: Cerebellar hemi-hypoplasia. Prenat. Diagn., 18:173-7, 1998.

Rollins, N. K.; Wen, T. S. \& Dominguez, R. Crossed cerebellar atrophy in children: a neurologic sequela of extreme prematurity. Pediatr. Radiol., 25(Suppl 1):S20$5,1995$.

Rhyu, I. J.; Cho, T. H.; Lee, N. J.; Uhm, C. S.; Kim, H. \& Suh, Y. S. Magnetic Resonance image-based cerebellar volumetry in healthy Korean adults. Neurosci. Lett., 270:149-52, 1999.

Sahin, B. \& Ergur H. Assessment of the optimum section thickness for the estimation of liver volume using magnetic resonance images: a stereological gold standard study. Eur. J. Radiol., 57:96-101, 2006.

Sato, N.; Yagishita, A.; Oba, H.; Miki, Y.; Nakata, Y.; Yamashita, F.; Nemoto, K.; Sugai, K. \& Sasaki, M. Hemimegalencephaly: a study of abnormalities occurring outside the involved hemisphere. AJNR Am. J. Neuroradiol., 28:678-82, 2007.

Sim, M. E.; Lyoo, I. K.; Streeter, C. C.; Covell, J.; SaridSegal, O.; Ciraulo, D. A.; Kim, M. J.; Kaufman, M. J.; Yurgelun-Todd, D. A. \& Renshaw, P. F. Cerebellar gray matter volume correlates with duration of cocaine use in cocaine-dependent subjects. Neuropsychopharmacology, 32:2229-37, 2007.

Tang, Y.; Whitman, G. T.; Lopez, I. \& Baloh, R. V. Brain volume changes on longitudinal magnetic resonance imaging in normal older people. J. Neuroimaging, 11:393-400, 2001

Traccis, S.; Zoroddu, G. F.; Zecca, M. T.; Cau, T.; Solinas, M. A. \& Masuri, R. Evaluating patients with vertigo: bedside examination. Neurol. Sci., 25(Suppl 1):S16-9, 2004

Weinberger, D. R.; Kleinman, J. E.; Luchins, D. J.; Bigelow, L. B. \& Wyatt, R. J. Cerebellar pathology in schizophrenia: a controlled post-mortem study. Am. J. Psychiatry, 137:359-61, 1980

Correspondence to:

H. Selim Karabekir, MD

Kocatepe University

Faculty of Medicine

Department of Neurosurgery

Afyonkarahisar

TURKEY

Tel: +90 2722463301

Fax: +90 2722463300

Email: hskarabekir@hotmail.com

Received: 15-12-2009

Accepted: 17-03-2010 